\title{
Shear and yarn pull-out grip for testing flexible sheets by universal load machines
}

\author{
Kolos Molnár ${ }^{\mathrm{a}, \mathrm{b}}$, Ábris Dávid Virág ${ }^{\mathrm{a}}$, Marianna Halász ${ }^{\mathrm{a}, *}$ \\ ${ }^{a}$ Department of Polymer Engineering, Faculty of Mechanical Engineering, Budapest University of Technology and Economics, Müegyetem rkp. 3. H-1111, Budapest, \\ Hungary \\ ${ }^{\mathrm{b}}$ MTA-BME Research Group for Composite Science and Technology, Müegyetem rkp. 3., H-1111, Budapest, Hungary
}

\section{A R T I C L E I N F O}

\section{Keywords:}

Shear test

Yarn-pull-out test

Yarn slippage

Critical adhesion length

Synthetic fibers

\begin{abstract}
A B S T R A C T
The purpose of this research was to develop a novel, multifunctional apparatus that makes possible to carry out two common tests of woven fabrics and flexible sheet-like materials, namely the shear and the yarn-pull out test. We designed an apparatus that can be mounted on a universal load machine and makes possible to test the materials rapidly and precisely.

In this paper we introduce the apparatus and the related simple shear and yarn pull-out test methods, as well as the accuracy and reproducibility of the test results obtained. We carried out cyclic shear and yarn pull-out tests on plain and panama weave materials. We found that the relative deviations of the common shear $(G, 2 H G$, $2 H G 5$ ) and yarn pull-out parameters were around 5-9\% in most cases that confirms the repeatability of the test method. With our method, one can carry out these tests without an expensive, dedicated test device.
\end{abstract}

\section{Introduction}

At human environmental textiles, at flexible sheets \& composites (e. g. canopies), and at composite reinforcements it is necessary to know their various mechanical properties in order to be able to design and create complex structures [1-4].

In the former cases the textile or the flexible sheet has to suit to the shape of the body or adequate draping properties are required for the appropriate optical performance. At composite reinforcements, the textile has to conform the shape of the mold. In all these cases, besides the good handling possibilities, appropriate shear properties, flexibility and the role of the friction between the fiber bundles or yarns have high importance (and moreover these things also influence one another) [5-7].

\subsection{The shear-tests of flexible sheets and textiles}

The method for investigating the shear properties of textiles and other flexible sheets has to be simple and rapid to fit the current requirements of the industry. There are widely-known methods making available to determine the shear properties, but these are either complicated, or the stress state, generated by the test setup, is not ideal

\section{$[8,9]$.}

In case of woven textiles maybe the simplest method is when the specimen in bias direction (the weft and warp yarns are located in $\pm 45^{\circ}$ directions to the axis of pulling) is tested by a tensile tester [8]. As the endings of the yarns are not constrained in the shear zone, therefore the shear state is suitable, but complex. The problem is with the determination of the exact location of the pure-shearing zone and as the shear deformation is calculated from the strain of the whole sample it is hard to obtain precise results. The method can be further improved by image processing as Domskiené and Strazdiené [10] and Al-Gaadi and Halász [11] demonstrated. This method is more precise but maybe too complex for industrial purposes and besides, it does not make possible to carry out cyclic tests that is a significant disadvantage.

The other widespread method, when the textile or the canopy sample is fixed to a picture frame that has knuckle-joints in the corners. The two opposite corners of the frame are displaced by the load machine thus the square becomes a rhombus the way the specimen is sheared. This method makes possible to make cyclic tests. The method is simple but not precise because the stress state is not ideal near the clamping bars hence the yarns are bended [10-12]. Orawattanasrikul [13] elaborated a special method to avoid the bending of the yarns during tests. The edges of the textile is not clamped, but pinned into needles. These

\footnotetext{
* Corresponding author. Department of Polymer Engineering, Faculty of Mechanical Engineering, Budapest University of Technology and Economics, Mủegyetem rakpart 3, H-1111, Budapest, Hungary.

E-mail address: halaszm@pt.bme.hu (M. Halász).
} 
needles make possible to transfer the shear forces, still makes possible the rotation of the yarns, therefore their bending can be neglected.

The Kawabata's Evaluation System for Fabrics (KES-FB) [14] can also be used for determining the shear properties of flexible sheets and textiles. At this method two parallel $200 \mathrm{~mm}$ long sides of a rectangular textile sample are clamped and one of them is moved to shear the specimen (Fig. 1/a) by an $F_{t}[\mathrm{~N}]$ force. The initially $50 \mathrm{~mm}$ distance of the parallel clamps $\left(X_{0}\right)$ gradually changes $(X(t))$ as a constant transversal pretension is applied during the test. The system is precise and the experiment can be carried out rapidly. The pretension $\left(f_{p}[\mathrm{~N} / \mathrm{m}]\right)$ is generated by a rotating drum and the requisite displacement is calculated from torque measurements that requires additional electronic control devices. As the device only operates in the $\pm 8^{\circ}$ shear angle range, therefore the bending of the yarns along the two edges can be neglected.

The totally automated, computer controlled KES-FB device does a cyclic shear test. During the test the shear motion changes direction as the shear angle reaches $+8^{\circ}$ or $-8^{\circ}$. The schematic of the measurement and a typical specific shear force - shear angle diagram can be seen in Fig. 1. Based on the diagram, the so-called Kawabata parameters can be determined: the hysteresis of shear force at shear angle of $0.5^{\circ}(2 \mathrm{HG}[\mathrm{N} /$ $\mathrm{m}])$, the hysteresis of shear force at shear angle of $5^{\circ}(2 \mathrm{HG} 5[\mathrm{~N} / \mathrm{m}])$, the shear rigidity, calculated from the mean slope of the curve in the region between a shear angle of $0.5^{\circ}$ and $5^{\circ}\left(G\left[\mathrm{~N} /\left(\mathrm{m}^{\circ}\right)\right]\right.$, respectively).

\subsection{The yarn pull-out tests of woven fabrics}

The yarn pull-out test is also a widely researched topic. Various measuring devices were made to do these kinds of tests, but all of them are one of a kind. Currently, the commonly accepted yarn pull-out measurement device is unknown.

The yarn pull-out test can be used to determine the interaction between the yarns of woven fabrics. During the test, the force needed to overcome the mostly frictional connection between the yarn to be pulled out and the crossing yarns is measured. The interaction between the yarns has a fundamental role on the material properties. It influences the shearing, bending, wrinkling, etc. properties, moreover the impact strength and the energy absorbing capacity of woven fabrics, hence it is very important to know this interaction, especially for modelling their mechanical behavior [15,16].

The principle of the yarn pull-out test can be seen in Fig. 2, while Fig. 3 shows a typical result of a single measurement. During the test, the rectangular woven fabric specimen has to be clamped on both sides, then a single yarn is pulled out along the centerline in parallel with the clamps. It is important that the upper end of the yarn is clamped and pulled, the other end of the yarn has to be able to move free. At the first, static stage of the yarn pull-out test (Fig. 3) due to the increasing pull-out force, the yarn being pulled-out straightens out and stretches, which leads to shear deformation on both sides of the yarn. The specimen itself deforms leading to a displacement $\left(d_{t}\right)$. The second, kinetic stage starts when the pull-out force reaches the peak value and overcomes the static friction force among the yarns. At this moment the yarn starts passing through the crossing yarns, leading to the increasing displacement of the yarn $\left(d_{y}\right)$. The pull-out force $\left(F_{p o}\right)$ is gradually decreasing with periodic waves and tending to zero as the yarn passes through more and more transversal yarns. The magnitude of $F_{p o}$ also influences the vertical deformation of the specimen itself $\left(d_{t}\right)$ that also decreases during this stage of the test.

In the case of another, modified test setup the free end of the pulled yarn overhangs the bottom edge of the fabric sample [18,19]. Fig. 4 shows a typical pull-out curve when the overhang was $50 \mathrm{~mm}$. Due to this modification the kinetic phase of the yarn pull-out divides in two more phases. In the first region of the kinetic phase the yarn to be pulled out passes through the same number of crossing yarns, hence the end of the yarn does not reach the bottom edge of the fabric sample. In this phase the mean value of the periodic tensile force after a quick decrease sets at an approximately constant value. When the end of the yarn to be pulled out reaches the bottom edge of the fabric sample, the second region of the kinetic phase starts. This time the pulled yarn passes through fewer and fewer crossing yarns, hence the mean value of the periodic tensile force decreases and tends asymptotically to zero.

Several papers have been published on the yarn pull-out test and its results [11,17-23]. Using the capstan equation some $[11,16]$ tried to determine the coefficient of friction among yarns from the yarn pull-out test results. However, the accuracy of the applied methods has not been proved yet. Knowing the maximal yarn pull-out force and the tensile strength of the yarn, Pan and Yoon [22] determined the critical yarn length. The critical yarn length is similar to the critical fiber length widely used in composite mechanics [24]. The critical yarn length equals the half of the critical fiber length and it means the smallest length of the embedded yarn that breaks due to the load instead of slipping out of the fabric.

\subsection{The aim of the research}

Yarn pull-out test is not a standardized test, therefore it does not include a standard measuring apparatus. Researchers usually build different clamps for this purpose, but these are typically only U-profile static clamps that are only suitable for yarn pull-out tests. Hence, many times they try to deduce the shear properties of fabrics from yarn pullout tests $[25,26]$.

To determine the shear properties of woven fabrics, we have previously described some well-known and widely used methods, including the Kawabata shear test. This measurement can be only carried out with a)

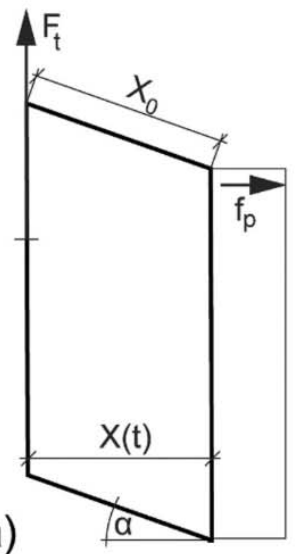

b)

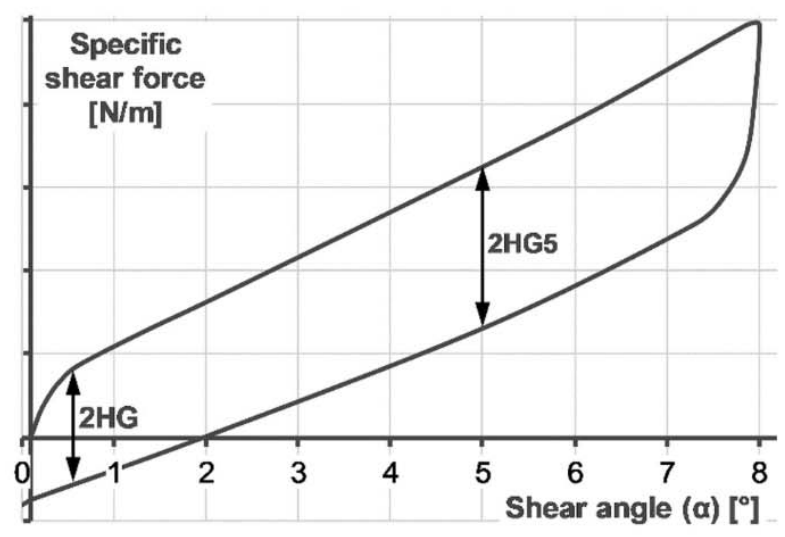

Fig. 1. Schematic of the tensile shear tester device of KES-FB system (a) and a typical specific shear force - shear angle diagram (b). 

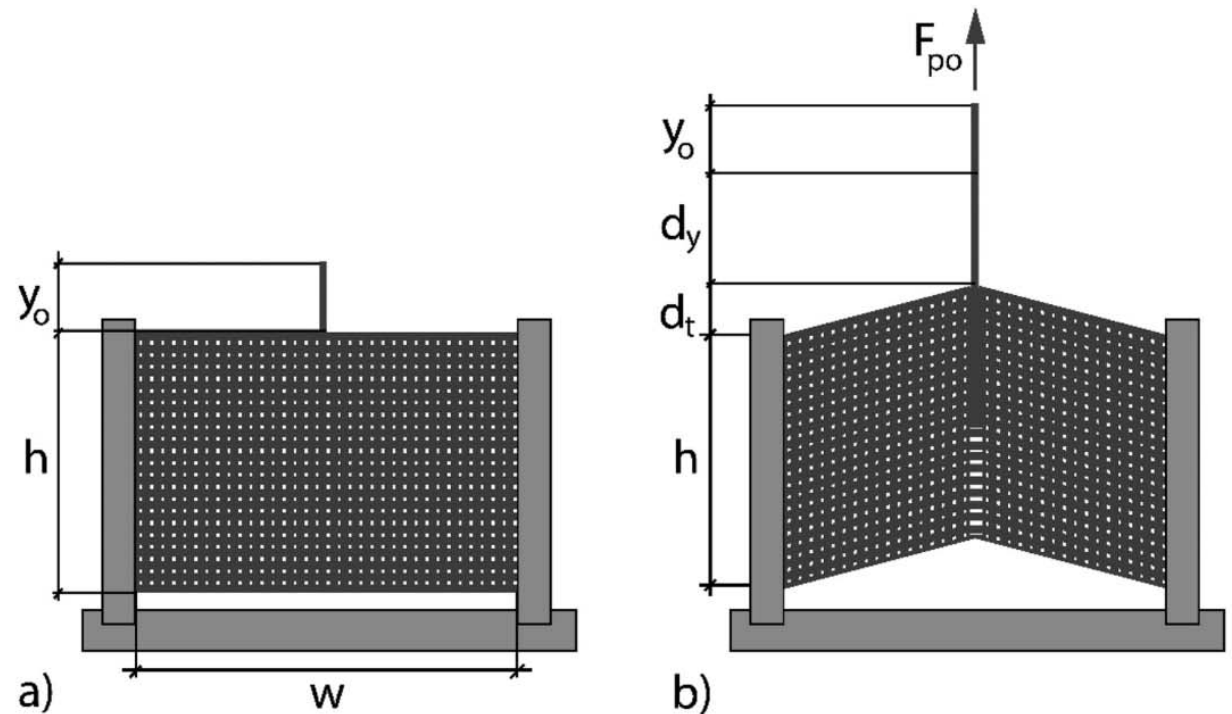

b)

Fig. 2. Schematic of the yarn pull-out test a) clamped, unloaded sample, b) sample during test [17] $h$ : height of the sample, $w$ : width of the sample, $y_{o:}$ yarn overhang, $d_{y}$ : displacement of the yarn, $d_{t}$ : displacement of the textile, $F_{p o}$ : yarn pull-out force.

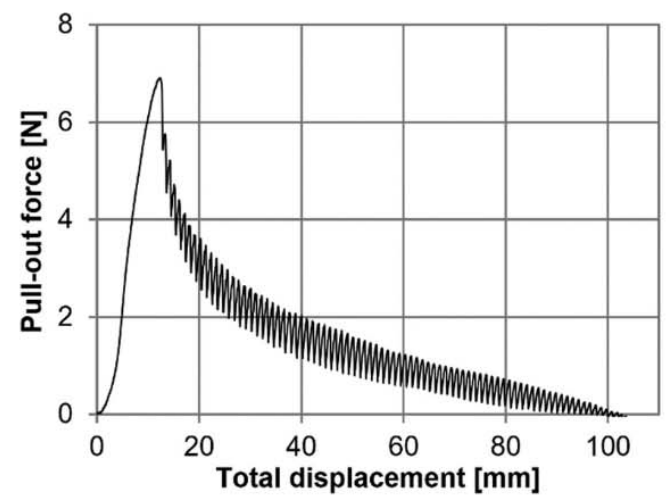

Fig. 3. A typical yarn pull-out curve.

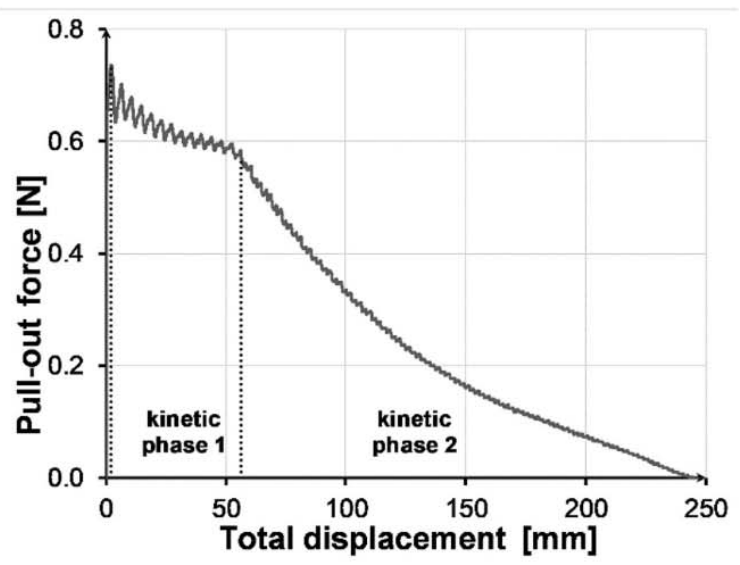

Fig. 4. Typical yarn pull-out curve in case of a $50 \mathrm{~mm}$ overhang.

the KES-FB1-A Tensile and Shear Tester, which is an expensive, standalone device for testing the tensile and shear properties of fabrics and from time to time it requires maintenance and calibration.

In our study, the aim was to design and construct an apparatus that makes possible to combine the simplicity of the above-mentioned test methods and the precision of the KES-FB system in order to determine the shear properties of textiles, textile composites and other flexible sheets. A grip that makes possible to maintain transversal pretension of the textile during the tests akin to the KES-FB shearing system was designed. Moreover, the same apparatus can be used for yarn pull-out tests of woven textiles. The pretension is applied by clearly mechanical ways during the tests leading to a simple, easy-to-build, symmetrical construction. There is no need for a complete device dedicated to only shear or yarn pull-out experiments as the grip can be mounted on almost any kind of universal load machine. With the apparatus the tests can be carried out rapidly and the evaluation of the results can be done with the aid of the software of the load machine. In this paper we demonstrate the applicability of this measurements and the accuracy of the results in case of both yarn pull-out and shear tests through some examples of technical materials.

In the current paper we describe the construction of the new apparatus we designed, as well as the shear and yarn-pull out tests we made. Shear tests (with the same principle of the KES-FB system) were made on a glass fabric, a polyester fabric and a canopy material, yarn-pull out test were made on another glass fabric and on a viscose fabric, moreover we introduced new parameters for the yarn-pull out test for the detailed evaluation of the results.

\section{Materials and methods}

\subsection{Materials}

For the shear tests we chose materials which are applied in technical fields: two woven fabrics, one was made of glass and the other one was made of polyester (PES) and besides a canopy that was a polyester (PES) fabric reinforced polyvinyl chloride (PVC) one. The structuralgeometrical properties of the chosen materials can be seen in Table 1.

For the yarn pull-out tests we chose one glass-based and one viscosebased reinforcing fabric. The structural-geometrical properties of the chosen fabrics can be seen in Table 2 .

\subsection{Methods}

\subsubsection{Apparatus design}

For all the measurements we used the novel apparatus (the universal grip unit) we designed. The schematic drawing of the apparatus for shear and yarn-pull-out tests can be seen in Fig. 5. The experimental setup is symmetrical. There are two clamps at the vertical edges of the 
Table 1

Structural-geometrical properties of the shear-tested materials.

\begin{tabular}{|c|c|c|c|c|c|c|c|c|}
\hline \multirow[t]{2}{*}{ Fabric Type } & \multirow[t]{2}{*}{ Material } & \multirow[t]{2}{*}{ Weave } & \multirow[t]{2}{*}{ Areal density $\left[\mathrm{g} / \mathrm{m}^{2}\right]$} & \multirow[t]{2}{*}{ Thickness [mm] } & \multicolumn{2}{|c|}{ Yarn linear density [tex] } & \multicolumn{2}{|c|}{ Yarn count $[1 / 10 \mathrm{~mm}]$} \\
\hline & & & & & Warp & Weft & Warp & Weft \\
\hline Glass 1 & Glass & Plain & 250 & 1.20 & 200 & 300 & 5 & 5 \\
\hline PES & Polyester & Panama $2 / 2$ & 400 & 0.72 & 105 & 105 & 24 & 24 \\
\hline Canopy & $\mathrm{PVC}+\mathrm{PES}$ & Plain & $265+85$ & 0.31 & 28 & 28 & 15 & 12 \\
\hline
\end{tabular}

Table 2

Structural-geometrical properties of the yarn pull-out tested materials.

\begin{tabular}{|c|c|c|c|c|c|c|c|c|}
\hline \multirow[t]{2}{*}{ Fabric Type } & \multirow[t]{2}{*}{ Material } & \multirow[t]{2}{*}{ Weave } & \multirow[t]{2}{*}{ Areal density $\left[\mathrm{g} / \mathrm{m}^{2}\right]$} & \multirow[t]{2}{*}{ Thickness [mm] } & \multicolumn{2}{|c|}{ Yarn linear density [tex] } & \multicolumn{2}{|c|}{ Yarn count $[1 / 10 \mathrm{~mm}]$} \\
\hline & & & & & Warp & Weft & Warp & Weft \\
\hline Glass 2 & Glass & Plain & 50 & 0.04 & 10.9 & 9.1 & 25 & 20 \\
\hline Viscose & Viscose & Plain & 200 & 0.44 & 67 & 67 & 14 & 14 \\
\hline
\end{tabular}

sample and one in the middle. Only the middle clamp is to be changed for the corresponding test. Yarn pull-out requires a top grip to catch the overhanging yarn at the top, while shearing needs a full-length middle grip (as in Fig. 5). Two parallel edges of a rectangular test sample (Fig. 5: 1) are clamped (Fig. 5: 2A) and the deformation is induced amongst the vertical symmetry line via the middle clamp (Fig. 5: 2B). To achieve a simple but precise construction the pretension is induced by a long helical spring (Fig. 5: 5) having linear characteristics. During the test, the two side clamps can move on a horizontal rail due to the vertical force generated by the load device and the horizontal forces of the pretension spring mechanism. Prior to the test, the spring has to be stretched) by two simple worm gears (Fig. 5: 5) until reaching a desired length related to $20 \mathrm{~N}$ tensile (transversal) force. The spring geometry was designed accordingly, and then the spring characteristics was calibrated by a tensile test, hence the length related to the $20 \mathrm{~N}$ force was determined. At this displacement a strong $(0.24 \mathrm{~mm}$ diameter $)$ high performance polyethylene (HPPE) fishing line (Fig. 5: 7) was then fixed to the hooks at the ends of the spring limiting its maximum strain. That way the yarn ensures that the spring can be stretched by the adjustment gears only until reaching the strain related to $20 \mathrm{~N}$.

The mechanical pretension system makes possible to maintain a transversal force during the tests with an accuracy of approximately $\pm 0.5 \%$ (at a preload of $20 \mathrm{~N}$ and $1 \mathrm{~mm}$ displacement of the side clamps) completely avoiding the application of supplementary electronics.

The materialized apparatus mounted on our load machine can be seen in Fig. 6. The whole apparatus can be tilted to a horizontal position around the motherboard after removing two fixing bolts (Fig. 7). In the back side of the apparatus there are two fasteners for fixing the grips on the linear rail. The side clamps (Fig. 6: 3B) can be fixed at any position by a locking lever in order to ensure their appropriate distance. In this

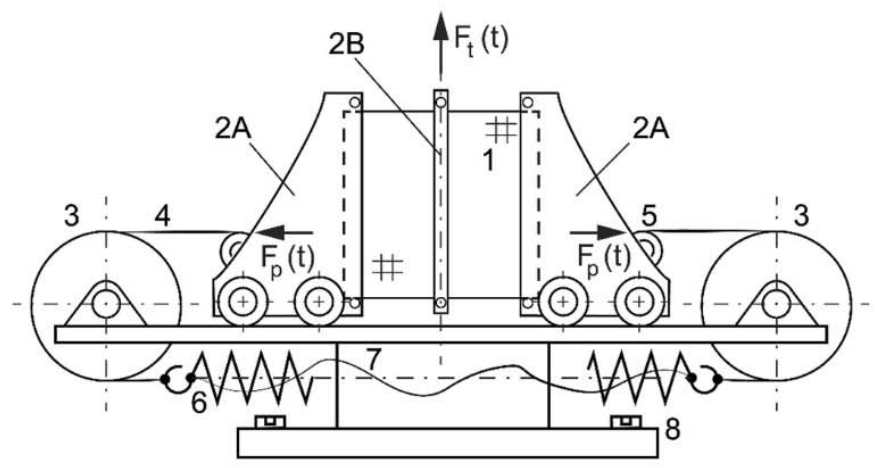

Fig. 5. The schematics of the designed apparatus. 1: specimen, 2A: side clamps, 2B: middle clamp (depicting the one for shear tests), 3: rollers with appropriate bearing, 4: thin rope, 5: gears 6: pretension steel spring, 7: strain limiting yarn, 8: base plate. horizontal position of the apparatus the textile test specimen can be fixed to the grips conveniently. Both grips have a rough surface (sanding paper) at one side and soft rubber on the other side therefore avoiding slippage when clenched together by screws. As soon as the specimen is well-fixed, the apparatus can be tilted back to its operating position and fixed by the bolts. Then the locking levers are to be loosened, so the side clamps can again slide free on the rail. The pretension can be applied (Fig. 6: 5-6) by the adjustment gears until reaching the proper strain of the spring. The middle clamping unit is then fixed depending on which test (yarn pull-out or shear) is to be carried out. Fig. 6/a shows the middle clamp for shear test while Fig. 6/b depicts the one for yarn-pullout test. The middle clamp for the yarn-pull-out test is a common yarn tensile testing clamp.

\subsubsection{Shear test method}

The shear tests were carried out with the novel apparatus which was mounted on a Zwick Z005 type universal load machine. The force was measured by a sensor having a range of $5 \mathrm{kN}$ and a resolution of $1 \mathrm{mN}$. The tests were carried out with $20 \mathrm{~N}$ pretension force $\left(F_{p}\right)$, i.e. $1 \mathrm{~N} / \mathrm{cm}$ relative to sample length, induced by the spring. The crosshead speed was $10 \mathrm{~mm} / \mathrm{min}$. The shear angle range was $\pm 8^{\circ}$ and a whole shear cycle was investigated. Ten samples of each type were investigated in $0^{\circ}, 90^{\circ}$ and $45^{\circ}$ directions, relative to the manufacturing direction. For the tests the gripping distance (width) was chosen to be $2 \times 50 \mathrm{~mm}$ (symmetrical) and the length of the sample was $200 \mathrm{~mm}$. For the measurements we cut specimens from the Glass 1 and PES fabrics and from the canopy. Due to the extra material required for side gripping the test samples size was $150 \mathrm{~mm} \times 200 \mathrm{~mm}$.

The shear properties of some selected textile specimens were tested to demonstrate the applicability of the device for shear tests.

The measurement principle (which is the same as the principle of the KES-FB system) with the novel apparatus can be seen in Fig. 8. On the left, the sample is unloaded prior to the test, while on the right it is loaded.

As the shear modulus is determined at small shear deformations, therefore the pretension induced by the spring can be considered constant from this perspective. According to the construction, during the shear tests the transversal yarns of the specimen have approximately constant length and almost pure shearing takes place. The half-gripping distance ( $X_{0}$, in Fig. $8 /$ a) is the distance between the middle and the side clamps. This $X_{0}$ distance is also identical with the length of the horizontal yarns between the clamps. When the displacement is induced (Fig. 8/b) the length of the initially horizontal yarns remain the same but the clamps come closer to each other $(X(t))$ due to the pretension. As the side clamps can be fixed at any positions it also makes possible to carry out tests with constant gripping distance.

The shear angle $\alpha(t)$ can be calculated from the displacement of the middle clamp as a function of time $\Delta Y(t)$ with equation (1): 


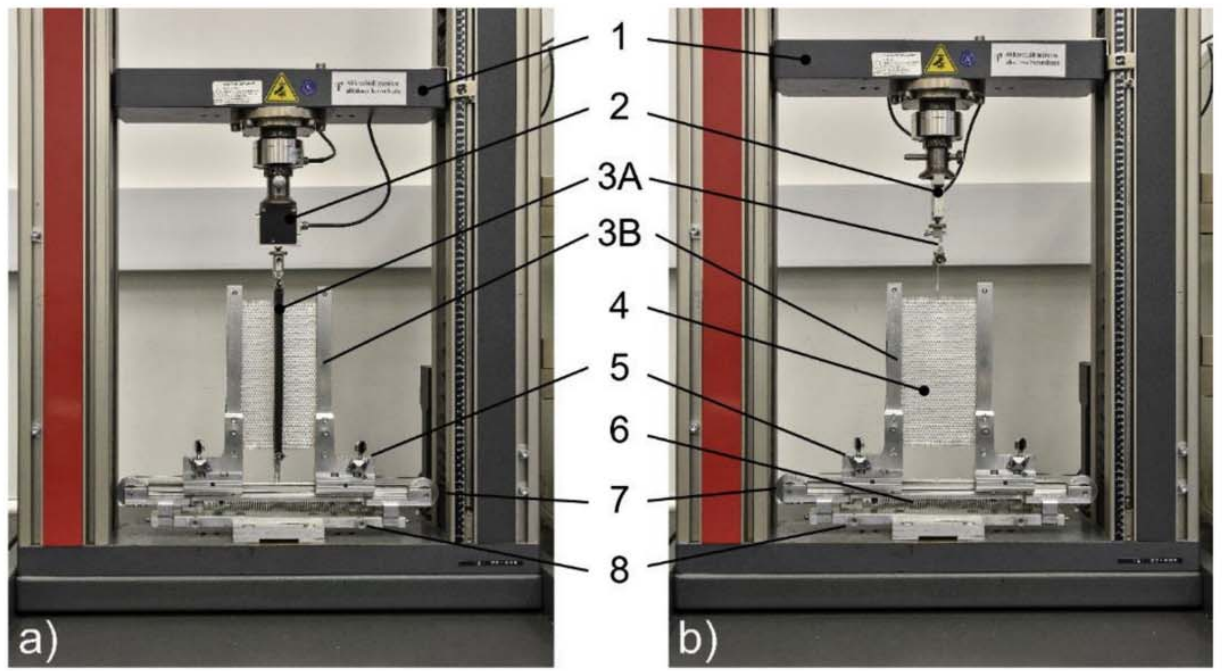

Fig. 6. The apparatus with middle clamp for shear test (a) and yarn pull-out test (b) of woven fabrics. 1: crosshead, 2: force sensor, 3A: middle clamp connected to the crosshead through the force sensor, 3B: side clamps, 4: test specimen, 5: worm gears for adjusting pretension, 6: pretension spring, 7: rollers with bearings, 8: fixing bolts.

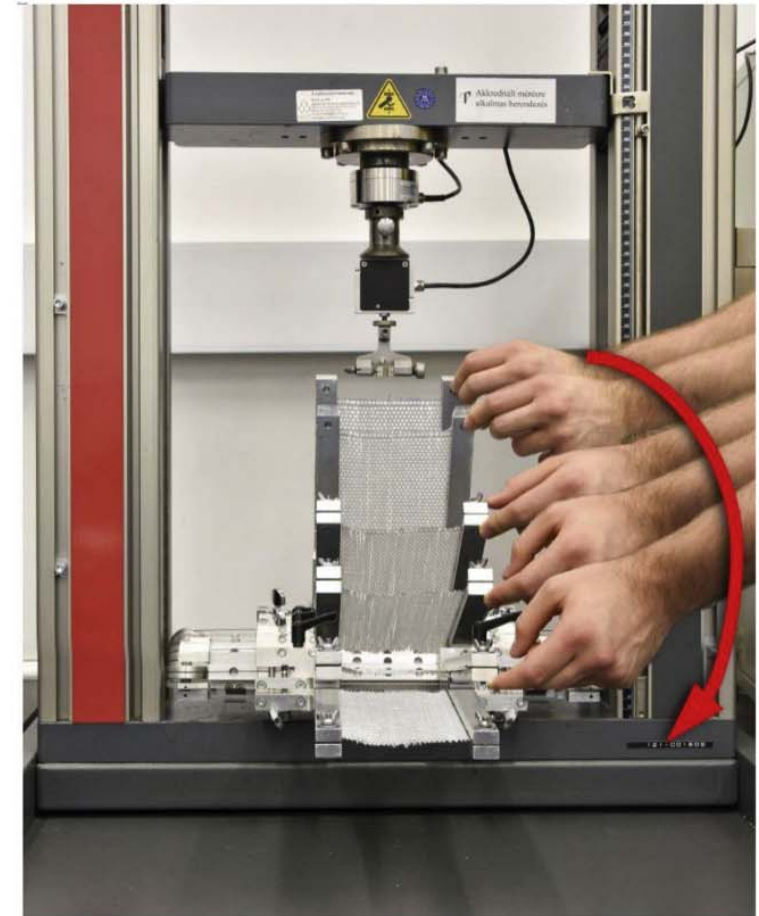

Fig. 7. A montage of tilting the apparatus to horizontal position for changing sample.

$\alpha(t)=\operatorname{rcsin}\left(\Delta Y(t) / X_{0}\right) \cdot 180 / \pi,\left[^{\circ}\right]$

The measurement is carried out cyclically, like at the KES-FB test. The half-gripping distance $\left(X_{0}\right)$ is the same $50 \mathrm{~mm}$ as that of the KES-FB. From equation (1) the displacement of the middle clamp can be calculated. If $X_{0}$ is $50 \mathrm{~mm}$ and the shear angle is $8^{\circ}$, then the measurement cycle has to be done with the maximum displacement of the middle clamp of $\pm 6.959 \mathrm{~mm}$.

As opposed to the KES equipment, the testing of the samples left and right to the middle clamp are done simultaneously, with opposite shearing directions. The measured shear force is the sum of the forces for the two sides/directions. Therefore, in determining the specific shear

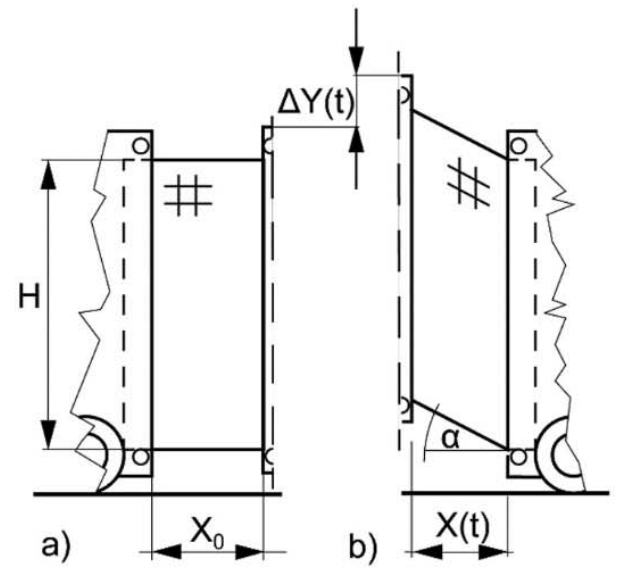

Fig. 8. The principle of the shear test. The sample is unloaded before the shear test (a) and loaded during the shear test (b).

force $\left(N_{f}[\mathrm{~N} / \mathrm{m}]\right)$, half the force measured by the tensile tester $(F[\mathrm{~N}])$ has to be taken into account together with the length of the sample that is parallel to the clamps $(H[\mathrm{~m}])(2)$ :

$N f=F /(2 H),[\mathrm{N} / \mathrm{m}]$

The specific shear force - shear angle diagram can be plotted from the results, and the Kawabata-parameters can be determined from the diagram in the usual way.

\subsubsection{Yarn pull-out test method and special parameters}

The yarn-pull out behavior of fabrics was tested to demonstrate the applicability of the device for yarn-pull out tests. Moreover, we present two special parameters, which can be determined from the yarn pull-out test: the critical adhesion length and the specific resistance against slippage.

The yarn pull-out tests were carried out with the apparatus which was mounted on the same a Zwick Z005 type universal load machine. The force was measured by a sensor having a measuring range of $20 \mathrm{~N}$ with a resolution of $1 \mathrm{mN}$. The tests were carried out with $20 \mathrm{~N}$ pretension force, i.e. $1 \mathrm{~N} / \mathrm{cm}$ (related to sample length), induced by the spring. The tests were carried out with a crosshead speed of $100 \mathrm{~mm} /$ min and the warp yarns were pulled out. 
For the tests the gripping distance (width) was chosen to be $100 \mathrm{~mm}$ and the length of the sample was $200 \mathrm{~mm}$. For the measurements we cut specimens from the Glass 2 and Viscose fabrics. Due to the extra material required for side gripping, the test specimens size was $140 \mathrm{~mm} \times 200$ $\mathrm{mm}$. In addition, for the prepared specimens, the yarn to be pulled out overhung the upper and lower edge of the fabric by $30 \mathrm{~mm}$ and $100 \mathrm{~mm}$, respectively, due to the type of test. Five samples of each type were investigated.

It is important to see where is the limit where the yarns break instead of slipping out of the textile specimen due to the pull-out force. In order to know the breaking force of the warp yarns that limits the maximum force at the yarn pull-out tests we carried out tensile tests. We made 15 individual measurements for each material (Glass 2 and Viscose), where the gripping length was $50 \mathrm{~mm}$. Every other set up parameter was the same as we used at the yarn pull-out tests. The breaking force $\left(F_{S}\right)$ and the elongation at break $\left(\varepsilon_{S}\right)$ were determined.

During the yarn pull-out test, the pull-out force and the displacement of the gripped yarn end are registered by the universal load machine. Various mechanical parameters can be determined from the measurement results that implies the friction between the yarns forming the fabric.

Knowing the breaking force of these yarns, the critical adhesion length can be determined.

From the test results a special parameter, the specific resistance against slippage can be determined. This parameter means the resistance against slippage of the unit length of the yarn that is slipping through the crossing yarns. Therefore, that is the required force per unit length to sustain the slippage of the yarn.

When determining these parameters, we assume that the yarn pullout force is directly proportional to the length of the yarn embedded into the fabric and we neglect the strains of the yarn and the embedding fabric.

Let the length of the embedding fabric sample be $H[\mathrm{~mm}]$, the length of the embedded yarn be $L[\mathrm{~mm}]$, the crimp of the yarn to be pulled-out be $B$. The crimp can be determined with a simple measurement and it can be calculated according to (3):

$B=(L-H) / H,[-]$

When determining the critical adhesion length, the peak value of the yarn pull-out force is used $\left(F_{a d h, \max }[\mathrm{N}]\right)$ for the calculation. This force is required to set the yarn in motion. From this, using equation (4) the critical specific adhesion resistance (which is the required force to set the unit length of yarn in motion) $\left(f_{a d h, m a x}[N]\right)$ can be calculated as (4):

$f_{a d h, \max }=\frac{F_{a d h, \max }}{L}=\frac{F_{a d h, \max }}{H(1+B)},[\mathrm{N} / \mathrm{mm}]$

Using the critical specific adhesion resistance and the breaking force of the yarn $\left(F_{S}[\mathrm{~N}]\right)$, the critical adhesion length $\left(L_{\text {crit }}[\mathrm{mm}]\right)$ can be determined as (5):

$L_{c r i t}=\frac{F_{s}}{f_{\text {adh, } \max }},[\mathrm{mm}]$

If the measurement is done in such a way that the free end of the yarn to be pulled out overhangs the bottom edge of the fabric sample before the beginning of the test, then the specific resistance against slippage can be determined in two different ways. In this case, the specific resistance against slippage can be determined from the first and the second region of the kinetic phase of the yarn pull-out diagram (Fig. 4). However, the two values may vary significantly depending on the characteristics of the curve.

In the first case, the specific resistance against slippage is determined from the first region of the kinetic phase. In this case, the consolidated mean value of the periodic pull-out force in this region ( $F_{\text {slipp, const }}[\mathrm{N}]$ ) is used for the calculation. Such mean force is needed for the yarn to continuously slip out of the $H$-length fabric. From this force, one kind of a specific resistance against slippage $\left(f_{\text {slipp, kin1 }}\right)$ can be calculated (6):

$f_{\text {slipp }, \text { kin } 1}=\frac{F_{\text {slipp, const }}}{H(1+B)},[\mathrm{N} / \mathrm{mm}]$

In the second case, the specific resistance against slippage is determined from the second region of the kinetic phase. In this phase, the pulled yarn begins to pass through fewer and fewer crossing yarns, hence the mean value of the periodic tensile force decreases and tends asymptotically to zero. Omitting the initial, transitional part of the curve, a linear trend line can be fitted (Fig. 9).

Where the trend line intersects the horizontal axis (Fig. 15, point $B$ ), the force decreases to 0 and the pulled yarn leaves the fabric. Point $A$ marks the beginning of the trend line (Fig. 15, A). The displacement from point $A$ to $B$ is the same as the length of the pulled yarn embedded in the fabric at point $A\left(L_{A}[\mathrm{~mm}]\right)$. The force that can be measured at point $A$ ( $F_{\text {slipp, } A}[\mathrm{~N}]$ ) is the force that is required to maintain the slip of the $L_{A}$-length yarn. From these relationships the other kind of specific resistance against slippage can be calculated $\left(f_{\text {slipp, kin2 }}\right)(7)$ :

$f_{\text {slipp }, k i n 2}=\frac{F_{\text {slipp, }} \quad \Lambda}{L_{\Lambda}},[\mathrm{N} / \mathrm{mm}]$

This kind of specific resistance against slippage can be calculated even if the measurement is done in such a way that the free end of the pulled yarn overhangs the bottom edge of the fabric sample.

The three indicators characterize the mechanical connection of the cross-linked yarns in the fabric. The critical specific adhesion resistance shows the force which is required to set the yarn in motion, the specific resistance against slippage shows the force which is required to sustain the slippage of the yarn. The purpose of use determines which one should be determined.

\section{Results and discussion}

\subsection{Shear test results and discussion}

The Kawabata parameters ( $2 H G, 2 H G 5$ and $G$ ) were calculated from the first positive cycle of the tests [10]. The results for the materials can be found in Tables 3-5, respectively.

The specific shear force - shear angle hysteresis diagrams of the tests registered for the $0^{\circ}$ direction samples can be seen in Fig. 10/a. Due to the PVC matrix, the canopy was understandably more resistant to the shear force than the Glass 1 or the PES fabric. In the two latter cases the yarns can be easily turn on each other at the interlacing points. The specific shear force - shear angle hysteresis diagrams of the tests made on the $90^{\circ}$ direction samples can be seen in Fig. 10/b. The measurement process of the shear tests made on the $45^{\circ}$ direction glass fabric samples can be seen in the pictures of Fig. 10/c. In this case the behavior of the three materials was similar, but significantly different from the $0^{\circ}$ and

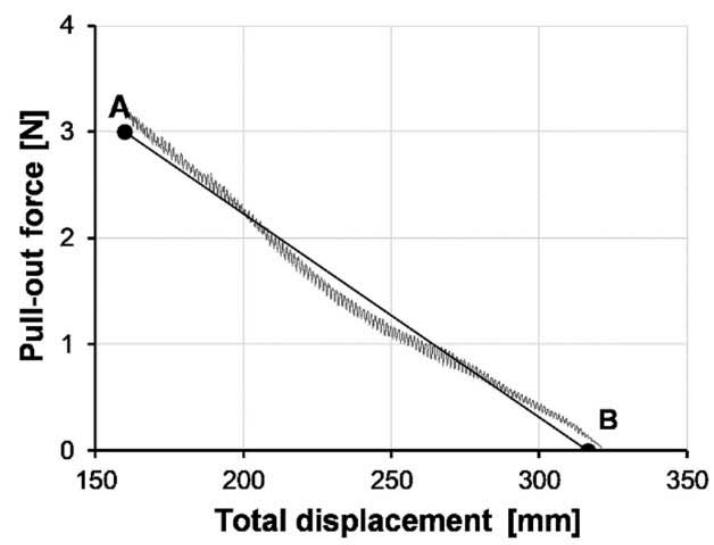

Fig. 9. Linear trend line fitted to the decreasing part of the yarn pull-out curve. 
Table 3

Shear properties of the glass fabric.

\begin{tabular}{|c|c|c|c|c|c|c|c|c|c|c|}
\hline \multirow[t]{2}{*}{ Glass 1} & & \multicolumn{3}{|l|}{$0^{\circ}$} & \multicolumn{3}{|l|}{$90^{\circ}$} & \multicolumn{3}{|l|}{$45^{\circ}$} \\
\hline & & Mean & $\begin{array}{l}\text { Standard } \\
\text { deviation }\end{array}$ & $\begin{array}{l}\text { Relative standard } \\
\text { deviation [\%] }\end{array}$ & Mean & $\begin{array}{l}\text { Standard } \\
\text { deviation }\end{array}$ & $\begin{array}{l}\text { Relative standard } \\
\text { deviation [\%] }\end{array}$ & Mean & $\begin{array}{l}\text { Standard } \\
\text { deviation }\end{array}$ & $\begin{array}{l}\text { Relative standard } \\
\text { deviation [\%] }\end{array}$ \\
\hline $2 \mathrm{HG}$ & $\begin{array}{l}{[\mathrm{N} /} \\
\mathrm{m}]\end{array}$ & 12.91 & 1.24 & 9.6 & 8.39 & 0.66 & 7.9 & 266.56 & 55.72 & 20.9 \\
\hline 2HG5 & $\begin{array}{l}{[\mathrm{N} /} \\
\mathrm{m}]\end{array}$ & 12.1 & 0.66 & 5.5 & 7.58 & 0.66 & 8.7 & 117.34 & 25.2 & 21.5 \\
\hline G & $\begin{array}{l}{[\mathrm{N} /} \\
\left.\mathrm{m} /{ }^{\circ}\right]\end{array}$ & 4.54 & 0.27 & 5.9 & 2.77 & 0.15 & 5.4 & 31.36 & 6.05 & 19.3 \\
\hline
\end{tabular}

Table 4

Shear properties of the PES fabric.

\begin{tabular}{|c|c|c|c|c|c|c|c|c|c|c|}
\hline \multirow[t]{2}{*}{ PES } & & \multicolumn{3}{|l|}{$0^{\circ}$} & \multicolumn{3}{|l|}{$90^{\circ}$} & \multicolumn{3}{|l|}{$45^{\circ}$} \\
\hline & & Mean & $\begin{array}{l}\text { Standard } \\
\text { deviation }\end{array}$ & $\begin{array}{l}\text { Relative standard } \\
\text { deviation [\%] }\end{array}$ & Mean & $\begin{array}{l}\text { Standard } \\
\text { deviation }\end{array}$ & $\begin{array}{l}\text { Relative standard } \\
\text { deviation [\%] }\end{array}$ & Mean & $\begin{array}{l}\text { Standard } \\
\text { deviation }\end{array}$ & $\begin{array}{l}\text { Relative standard } \\
\text { deviation [\%] }\end{array}$ \\
\hline $2 \mathrm{HG}$ & $\begin{array}{l}{[\mathrm{N} /} \\
\mathrm{m}]\end{array}$ & 5.6 & 1.15 & 20.5 & 17.64 & 1.94 & 11.0 & 170.21 & 11.18 & 6.6 \\
\hline 2HG5 & $\begin{array}{l}{[\mathrm{N} /} \\
\mathrm{m}]\end{array}$ & 22.66 & 1.79 & 7.9 & 39.3 & 3.44 & 8.8 & 94.18 & 4.92 & 5.2 \\
\hline G & $\begin{array}{l}{[\mathrm{N} /} \\
\left.\mathrm{m} /{ }^{\circ}\right]\end{array}$ & 6.56 & 0.4 & 6.1 & 8.79 & 0.77 & 8.8 & 40.58 & 2.56 & 6.3 \\
\hline
\end{tabular}

Table 5

Shear properties of the PES/PVC canopy.

\begin{tabular}{|c|c|c|c|c|c|c|c|c|c|c|}
\hline \multirow[t]{2}{*}{ Canopy } & & \multicolumn{3}{|l|}{$0^{\circ}$} & \multicolumn{3}{|l|}{$90^{\circ}$} & \multicolumn{3}{|l|}{$45^{\circ}$} \\
\hline & & Mean & $\begin{array}{l}\text { Standard } \\
\text { deviation }\end{array}$ & $\begin{array}{l}\text { Relative standard } \\
\text { deviation [\%] }\end{array}$ & Mean & $\begin{array}{l}\text { Standard } \\
\text { deviation }\end{array}$ & $\begin{array}{l}\text { Relative standard } \\
\text { deviation [\%] }\end{array}$ & Mean & $\begin{array}{l}\text { Standard } \\
\text { deviation }\end{array}$ & $\begin{array}{l}\text { Relative standard } \\
\text { deviation }[\%]\end{array}$ \\
\hline $2 \mathrm{HG}$ & $\begin{array}{l}{[\mathrm{N} /} \\
\mathrm{m}]\end{array}$ & 70.07 & 110.82 & 158.2 & 70.84 & 4.86 & 6.9 & 212.46 & 27.22 & 12.8 \\
\hline 2HG5 & $\begin{array}{l}{[\mathrm{N} /} \\
\mathrm{m}]\end{array}$ & 3.86 & 8.08 & 209.3 & 109.04 & 8.42 & 7.7 & 117.94 & 9.27 & 7.9 \\
\hline G & $\begin{array}{l}{[\mathrm{N} /} \\
\left.\mathrm{m} /{ }^{\circ}\right]\end{array}$ & 45.33 & 3.55 & 7.8 & 46.32 & 2.11 & 4.6 & 56.25 & 2.72 & 4.8 \\
\hline
\end{tabular}

$90^{\circ}$ direction samples. All three materials were more resistant to shear force and their shear rigidity was much greater than in the cases of parallel direction samples that corresponds to what we experience in everyday use.

The measurement process of the shear tests made on the $0^{\circ}$ direction canopy samples can be seen in the pictures of Fig. 11. The series of pictures shows the first quarter of the measurement cycle. Right after starting the measurement wrinkles appeared on the canopy. The glass fabric did not produce such, and on the PES fabric only a few wrinkles formed. That can be originated from the rigid behavior of the composite material, not allowing enough flexibility for the fiber yarns to deform.

The measurement process of the shear tests made on the $90^{\circ}$ direction PES fabric samples can be seen in the pictures of Fig. 12. The series of pictures shows the third quarter of the measurement cycle. All the three materials had similar behavior like they have had in the cases of the $0^{\circ}$ direction.

The measurement process of the shear tests made on the $45^{\circ}$ direction Glass 1 fabric samples can be seen in Fig. 13. The series of pictures shows the first quarter of the measurement cycle. In these cases wrinkles appeared on all the three materials, respectively.

Since we wanted to confirm the proper repeatability of our test method, we compared the standard deviations of the G, $2 H G$ and $2 H G 5$ parameters with those of other methods. In the literature there are different studies with the KES-FB machine, on the picture frame test and the bias extension test. The different materials results in different values for the $G, 2 H G$ and $2 H G 5$ parameters, and therefore we focused on the comparison of the deviations. Table 6 summarizes the standard deviations.
From the table we can conclude that the standard deviation of the various test methods depend on the woven fabric tested. The structure of the fabric is highly imperfect due to the stochastic nature of the fiber structures and the weaving itself. At the testing of similar PES fabrics, the different research groups got greatly different results. Even if the weave pattern and the material are similar in the different cases, there can be huge differences in other parameters, e.g. yarn count and area density, hence we can only compare the scattering of the results.

With the KES-FB system the standard deviations of the PES woven fabrics was in between 2 and 53\% for the shear rigidity $(G)$. In our test it was around $11-20 \%$ for a similar material. The picture frame and the bias extension test produced a $9-11 \%$ and $11-15 \%$ standard deviations in the shear rigidity. That means that the standard deviations and the reproducibility of the test results are quite similar in the case of the four different methods introduced. That confirms that our simple and rapid method gives the same small deviations as the KES-FB method widely used in the industry and also as the other methods. That also confirms the good repeatability and reliability of the tests.

\subsection{Yarn pull-out test results and discussion}

The tensile test results of the warp yarns of the chosen fabrics for the yarn pull-out tests can be seen in Table 7. The glass fiber yarns had lower tensile breaking force and also relative elongation at break than those of the viscose yarns. That is because the viscose yarns had much higher linear density (see Table 2). These results are used later for the calculation of the critical adhesion length $\left(L_{\text {crit }}\right)$.

Fig. 14 illustrates the process of the yarn pull-out measurements at 

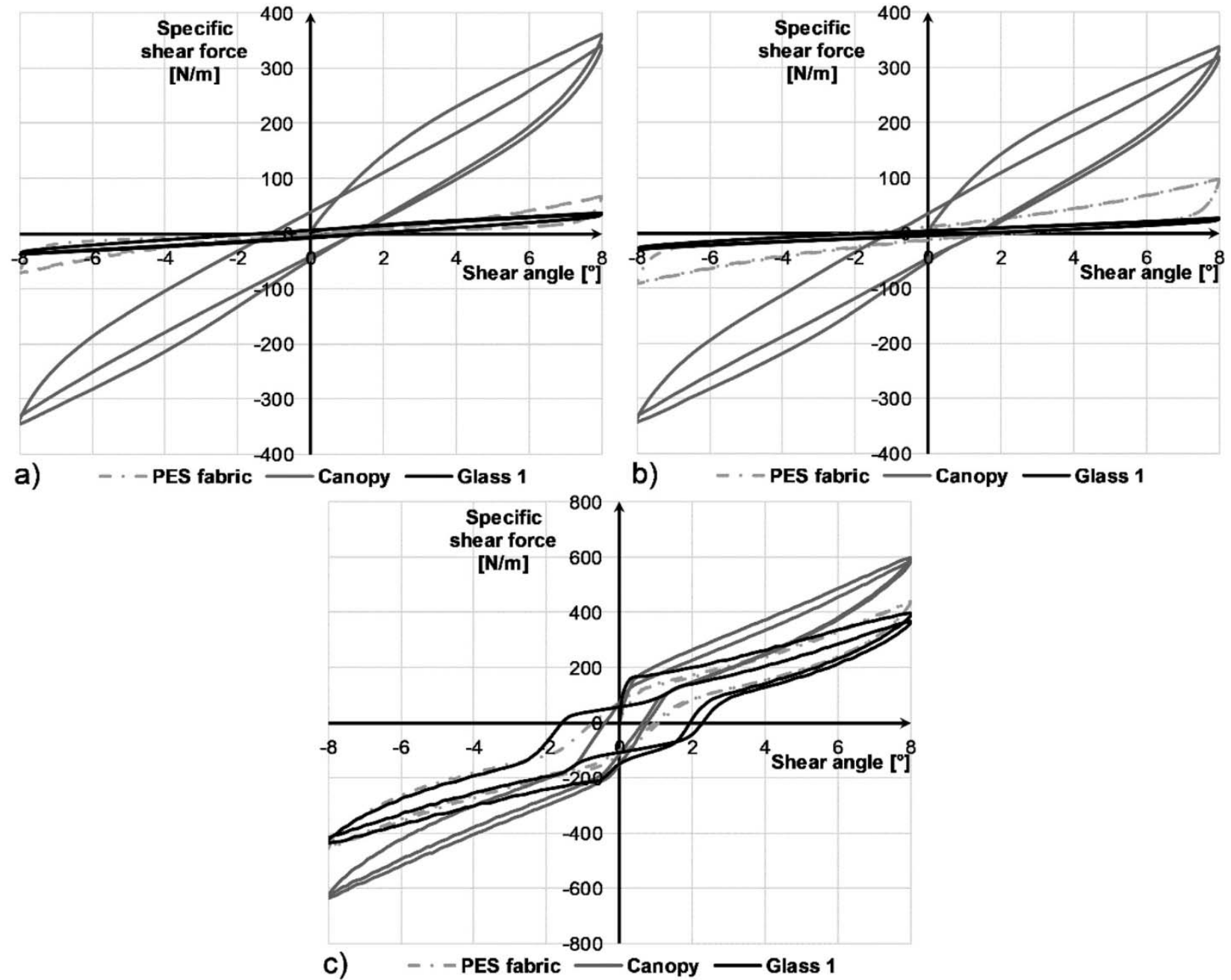

Fig. 10. Specific shear force - shear angle diagrams of $0^{\circ}$ direction (a), $90^{\circ}$ direction (b) and $45^{\circ}$ direction samples (c).
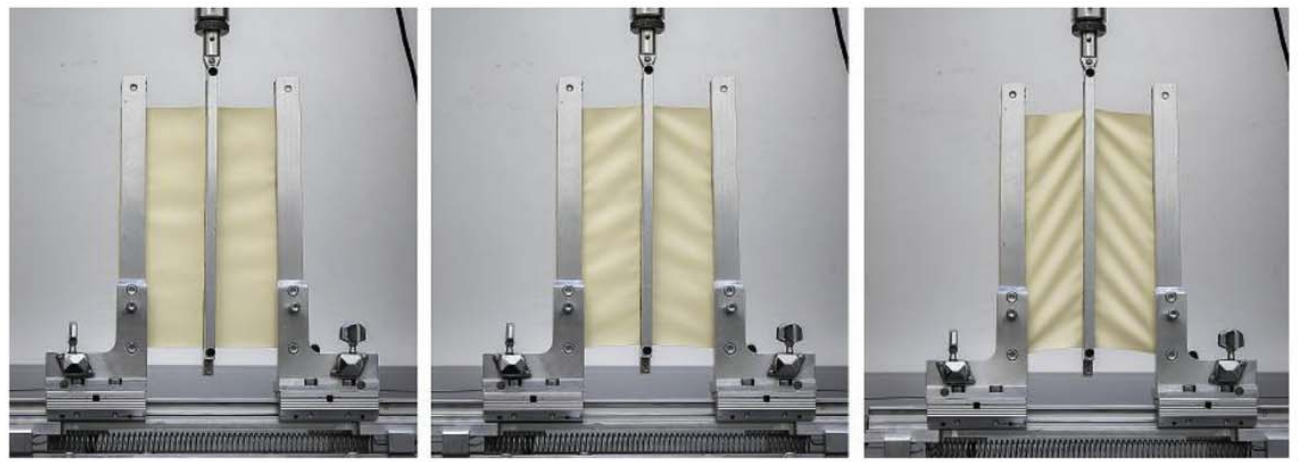

Fig. 11. The process of the shear test on the $0^{\circ}$ direction canopy samples.

various stages of the test. A typical yarn pull-out curve of the Glass 2 and the Viscose fabric can be seen in Fig. 15.

The force - displacement curves of the two fabrics are similar in characteristics, but the forces acting on the viscose fabric are much greater, than the forces acting on the Glass 2 fabric. Moreover, the shear deformation of the viscose fabric affected by the yarn pull-out was much higher, than that of the glass fabric and in the first region of the kinetic stage the mean value of the force slowly sets a constant value. In case of the viscose fabric, the decreasing part of the curve in the second region of the kinetic stage is almost entirely linear-like, hence in this case a longer section of the decreasing part can be replaced with a fitted linear trend line, than in the case of the glass fabric. This is the reason why there is much less difference between the two types of resistance against slippage in case of the viscose fabric, than in the case of the Glass 2 fabric.

From the measurement results the critical specific adhesion resistance $\left(f_{a d h, \max }\right)$, the critical adhesion length $\left(L_{c r i t}\right)$ and the specific resistance against slippage from the first $\left(f_{\text {slipp, kin } 1}\right)$ and the second $\left(f_{\text {slipp, }}\right.$, kin1) regions of the kinetic phase of the yarn pull-out curve were determined. The summary of the yarn pull-out results is shown in Table 8. 

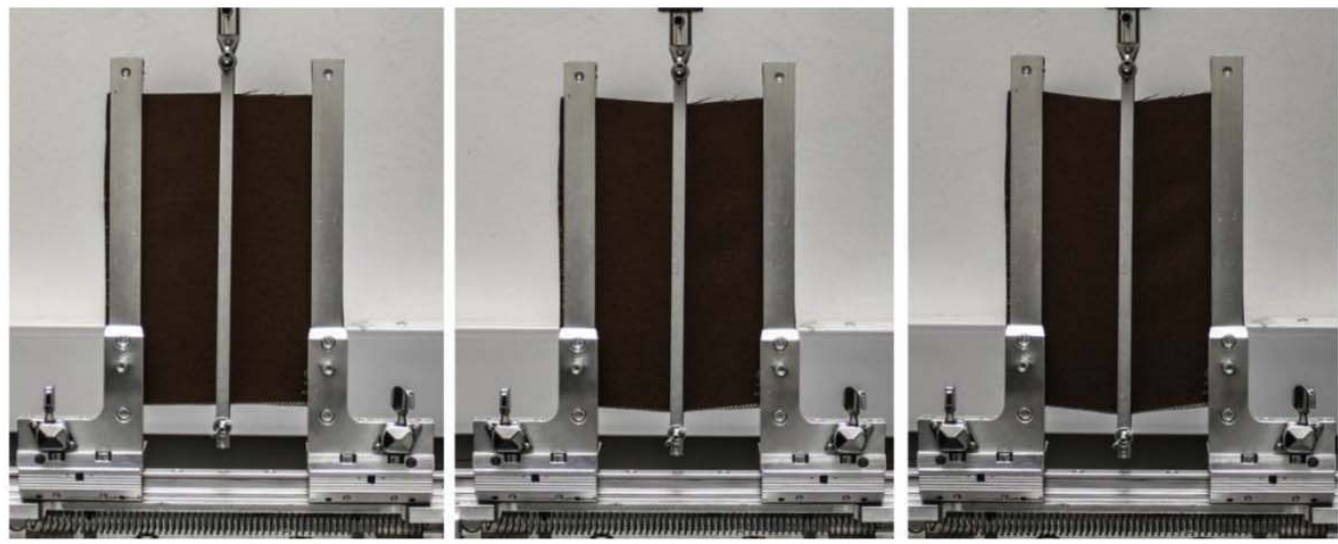

Fig. 12. The process of the shear test on $90^{\circ}$ direction PES fabric samples.
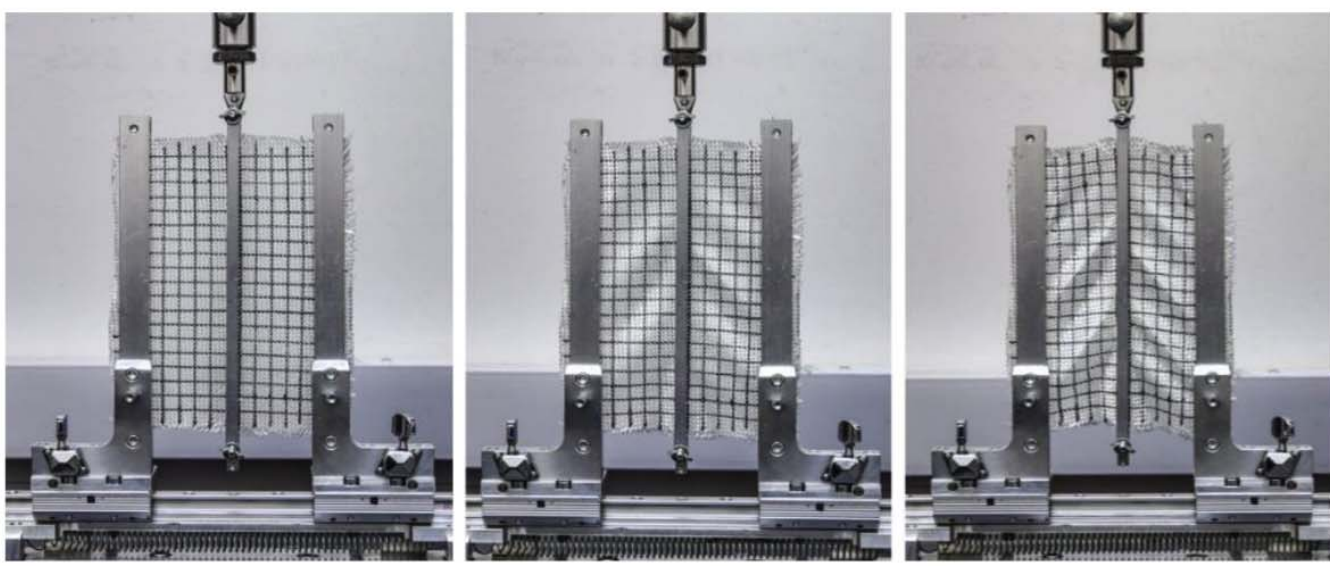

Fig. 13. The process of the shear test on the $45^{\circ}$ direction cut glass fabric samples.

Table 6

Comparison of the standard deviations of various shear measurements (all data in \%).

\begin{tabular}{|c|c|c|c|c|c|c|c|c|c|c|c|c|}
\hline \multirow[t]{2}{*}{ Material } & \multicolumn{2}{|c|}{ Current method } & \multicolumn{6}{|l|}{ KES-FB } & \multicolumn{2}{|c|}{ Picture frame } & \multicolumn{2}{|l|}{ Bias } \\
\hline & Glass & PES & Cotton [27] & Viscose [27] & PES [27] & PES [28] & PES [28] & Cotton [29] & PES [28] & PES [28] & PES $[28$ & \\
\hline Weave & Plain & Panama $2 / 2$ & Plain & Plain & Plain & Plain & Satin & Knitted & Plain & Satin & Plain & Satin \\
\hline G & $5.4-5.9$ & $11.0-20.5$ & $1.8-8.9$ & $1.3-5.3$ & $2.2-7.5$ & 28.3 & 53.0 & 3.6 & 9.2 & 11.0 & 17.8 & 15.0 \\
\hline $2 \mathrm{HG}$ & $7.9-9.6$ & $7.9-8.8$ & $7.9-9.1$ & $8.6-8.8$ & $5.6-8.7$ & 21.4 & 35.7 & 5.9 & 9.0 & 9.1 & 13.0 & 9.0 \\
\hline 2HG5 & $5.5-8.7$ & $6.1-8.8$ & $8.8-9.0$ & $2.9-4.6$ & $4.5-6.0$ & 14.7 & 24.9 & 6.8 & 6.8 & 6.1 & 9.0 & 8.2 \\
\hline
\end{tabular}

The critical adhesion length ( $L_{\text {crit }}$ ) was $1.034 \mathrm{~m}$ for the glass material, while it was $0.259 \mathrm{~m}$ that fits our experiences. Even though the tensile force of the viscose yarns were greater than that of the glass yarns, the dense structure and friction conditions between the yarns led to smaller critical adhesion length for the viscose material.

In the table it can be seen that the results gave small standard deviation despite the fact that the textile structure itself is imperfect. This can be explained by the sturdy clamping unit that fixes the edges of the specimen firmly and without the fabric slipping. The good repeatability of the tests is confirmed.

\section{Conclusions}

In this study, we introduce a new, simple method for testing the shear and yarn pull-out of fabrics. The apparatus we designed can be mounted on almost any kind of universal load machine, and it is suitable for various textiles and flexible sheets.

The test arrangement is quite similar to the KES-FB system, but instead of using supplementary electronics, the pretension is generated by a steel spring in order to regulate the stress-state. The simple, clearly mechanical system makes available to have a pretension typically in a $\pm 0.5 \%$ range during tests. The results revealed that the device can be used for both yarn pull-out and shear tests properly.

We found that the relative standard deviations of the typical shear ( $G, 2 H G, 2 H G 5)$ parameters were in the range of $5-20 \%$ for the glass

Table 7

Tensile test parameters of yarns.

\begin{tabular}{llllllll}
\hline $\begin{array}{l}\text { Fabric } \\
\text { Type }\end{array}$ & $\mathrm{F}_{\mathrm{s}}[\mathrm{N}]$ & & & & $\varepsilon_{\mathrm{s}}[\%]$ \\
\cline { 2 - 4 } \cline { 6 - 7 } & Mean & $\begin{array}{l}\text { Standard } \\
\text { deviation }\end{array}$ & $\begin{array}{l}\text { Relative } \\
\text { standard } \\
\text { deviation } \\
{[\%]}\end{array}$ & & Mean & $\begin{array}{l}\text { Standard } \\
\text { deviation }\end{array}$ & $\begin{array}{l}\text { Relative } \\
\text { standard } \\
\text { deviation } \\
{[\%]}\end{array}$ \\
\hline Glass 2 & 4.65 & 0.20 & 4.3 & 3.1 & 0.2 & 6.5 \\
Viscose & 8.19 & 0.71 & 8.7 & 20.0 & 2.0 & 10.0 \\
\hline
\end{tabular}



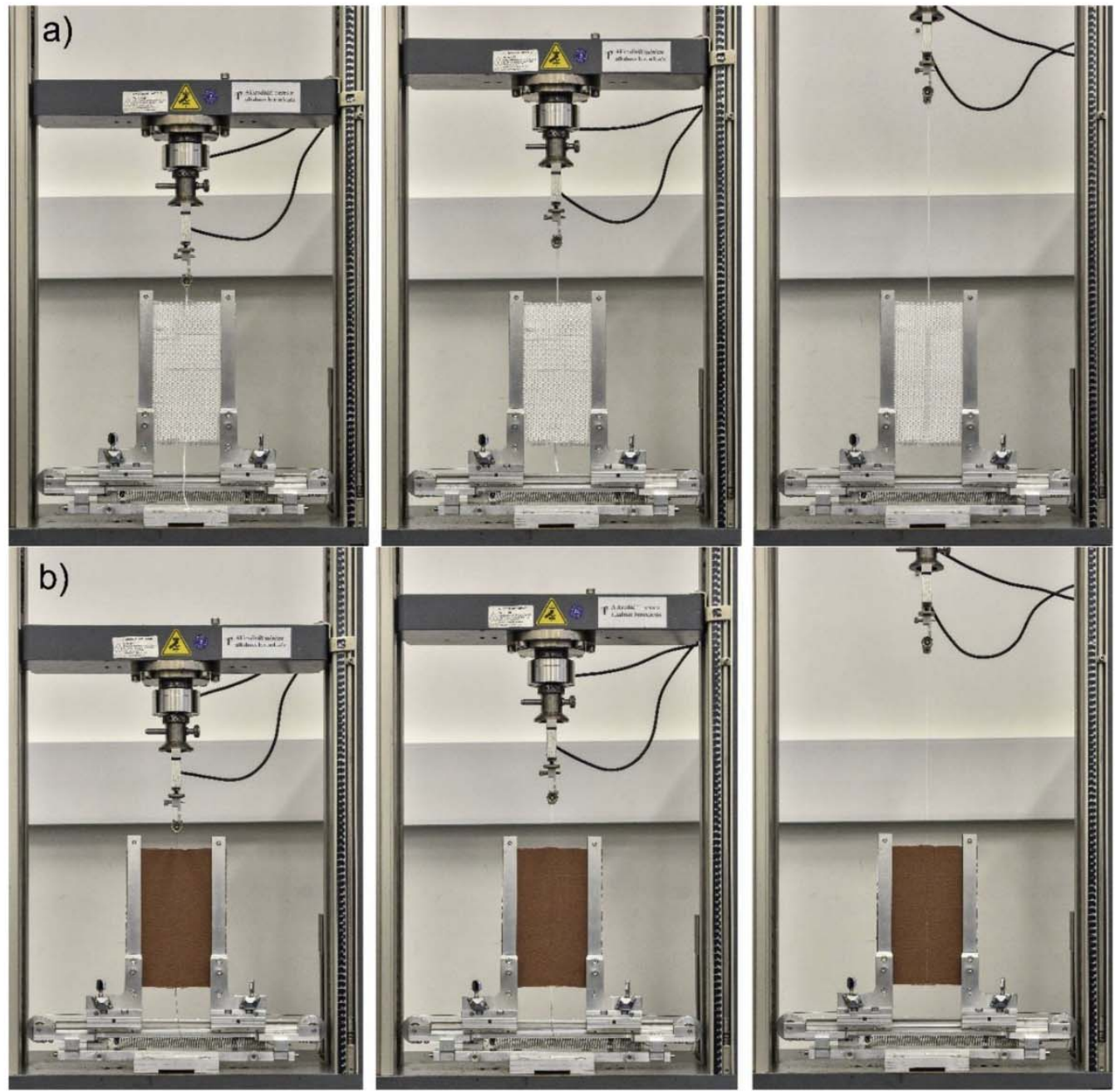

Fig. 14. Glass 2 fabric (a) and Viscose fabric (b) during yarn pull-out test.

fiber and PES fabrics, while the canopy gave greater deviations. The yarn pull-out parameters were tested, and the standard deviation of the parameters was mostly between $5 \%$ and $9 \%$ for the glass and viscose fabrics tested. The standard deviation of methods gave similar values to that of popular methods presented in the literature.
The main advantages of the device are the excellent repeatability, the cost-effectiveness, the appropriate stress state and the short testing time. For the yarn pull-out test, and the tensile tests the critical adhesion length was determined. The glass fabrics resulted in $1.034 \mathrm{~m}$, and the viscose fabrics resulted in $0.259 \mathrm{~m}$ due to the different yarn linear
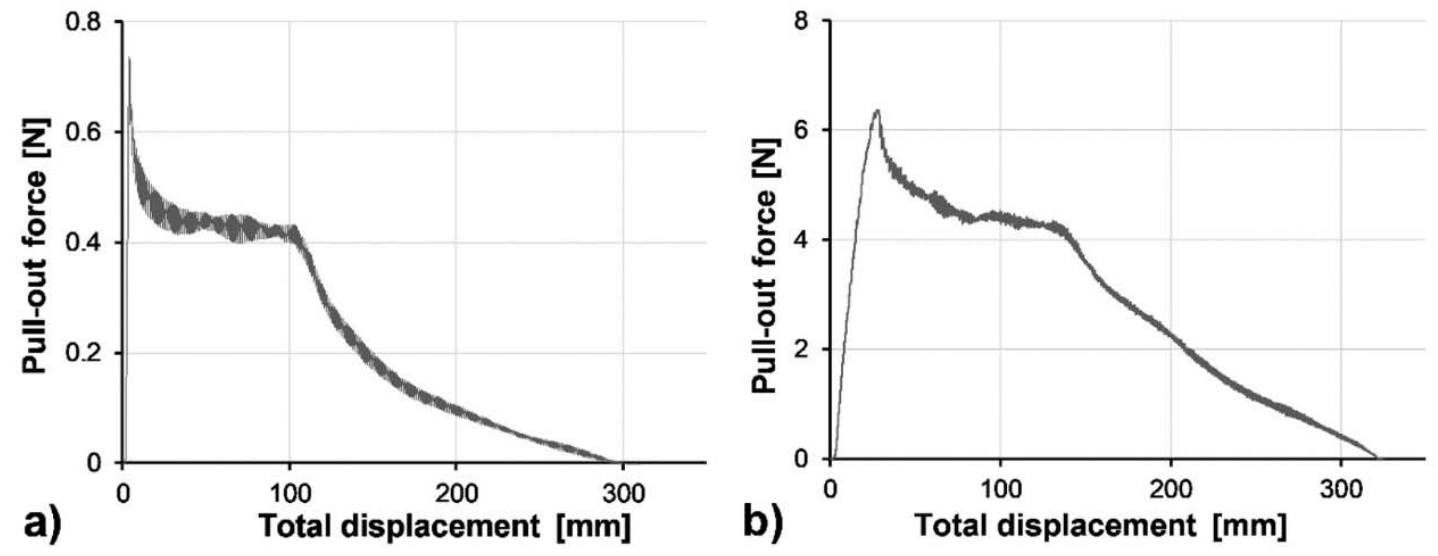

Fig. 15. Typical yarn pull-out curve of the Glass 2 (a) and the Viscose (b) fabric. 
Table 8

Results of the yarn pull-out test.

\begin{tabular}{|c|c|c|c|c|c|c|c|}
\hline \multirow[t]{2}{*}{ Parameter } & & \multicolumn{3}{|l|}{ Glass 2} & \multicolumn{3}{|l|}{ Viscose } \\
\hline & & Mean & Standard deviation & $\begin{array}{l}\text { Relative standard } \\
\text { deviation [\%] }\end{array}$ & Mean & Standard deviation & $\begin{array}{l}\text { Relative standard } \\
\text { deviation [\%] }\end{array}$ \\
\hline $\mathrm{F}_{\mathrm{adh}, \max }$ & {$[N]$} & 0.899 & 0.099 & 11.0 & 6.321 & 0.606 & 9.6 \\
\hline $\mathrm{f}_{\mathrm{adh}, \max }$ & {$[\mathrm{N} / \mathrm{mm}]$} & 0.004497 & - & - & 0.03161 & - & - \\
\hline $\mathrm{L}_{\text {crit }}$ & {$[\mathrm{mm}]$} & 1034 & - & - & 259.1 & - & - \\
\hline $\mathrm{F}_{\text {slipp, const }}$ & {$[\mathrm{N} / \mathrm{mm}]$} & 0.529 & 0.062 & 11.7 & 4.398 & 0.503 & 11.4 \\
\hline $\mathrm{f}_{\text {slipp, } \mathrm{kin} 1}$ & {$[\mathrm{~N} / \mathrm{mm}]$} & 0.002625 & - & - & 0.02185 & - & - \\
\hline$f_{\text {slipp, kin2 }}$ & {$[\mathrm{N} / \mathrm{mm}]$} & 0.001733 & 0.000307 & 17.7 & 0.02094 & 0.00249 & 11.9 \\
\hline
\end{tabular}

density and different frictional conditions in between the yarns.

\section{Declaration of competing interests}

The authors declare that they have no known competing financial interests or personal relationships that could have appeared to influence the work reported in this paper.

\section{CRediT authorship contribution statement}

Kolos Molnár: Validation, Investigation, Resources, Writing - original draft, Writing - review \& editing, Visualization. Ábris Dávid Virág: Investigation, Writing - original draft, Writing - review \& editing. Marianna Halász: Conceptualization, Methodology, Writing - original draft, Supervision.

\section{Acknowledgements}

This work was supported by the National Research, Development and Innovation Office (grant number: NVKP_16-1-2016-0046) and by the Higher Education Excellence Program of the Ministry of Human Capacities in the framework of the Nanotechnology research area of the Budapest University of Technology and Economics (BME FIKP-NANO). This paper was supported by the János Boyai Scholarship of the Hungarian Academy of Sciences and by the ÚNKP-19-2 and ÚNKP-19-4 New National Excellence Program of the Ministry for Innovation and Technology.

\section{Appendix A. Supplementary data}

Supplementary data to this article can be found online at https://doi. org/10.1016/j.polymertesting.2020.106345.

\section{References}

[1] L. Kovács, G. Romhány, Derivation of ply specific stiffness parameters of fiber reinforced polymer laminates via inverse solution of classical laminate theory, Period. Polytech. Mech. 62 (2) (2018) 158-164, https://doi.org/10.3311/ PPme.11846.

[2] M.J. Mochane, T.C. Mokhena, T.H. Mokhothu, A. Mtibe, E.R. Sadiku, S.S. Ray, I. D. Ibrahim, O.O. Daramola, Recent progress on natural fiber hybrid composites for advanced applications: a review, Express Polym. Lett. 13 (2) (2019) 159-198, https://doi.org/10.3144/expresspolymlett.2019.15.

[3] R. Várdai, T. Lummerstorfer, C. Pretschuh, M. Jerabek, M. Gahleitner, B. Pukánszky, K. Renner, Impact modification of PP/wood composites: a new approach using hybrid fibers, Express Polym. Lett. 13 (3) (2019) 223-234, https:// doi.org/10.3144/expresspolymlett.2019.19.

[4] S. Hussain, A.R. Dickson, Improving and predicting the mechanical properties of foamed and stretched composite poly(lactic acid) films, Express Polym. Lett. 13 (1) (2019) 18-26, https://doi.org/10.3144/expresspolymlett.2019.3.

[5] T. Yamada, N. Ito, M. Matsuo, Mechanical properties of knitted fabrics under uniaxial and strip biaxial extension as estimated by a linearizing method, Text. Res. J. 73 (11) (2003) 985-997, https://doi.org/10.1177/004051750307301109.

[6] P. Potluri, D.A.P. Ciurezu, R.B. Ramgulam, Measurement of meso-scale shear deformations for modelling textile composites, Compos. Part A-Appl S 37 (2) (2006) 303-314, https://doi.org/10.1016/j.compositesa.2005.03.032.

[7] B. Al-Gaadi, F. Göktepe, M. Halász, A new method in fabric drape measurement and analysis of the drape formation process, Text. Res. J. 82 (5) (2012) 502-512, https://doi.org/10.1177/0040517511420760.
[8] B. Zhu, T.X. Yu, X.M. Tao, Large deformation and slippage mechanism of plain woven composite in bias extension, Compos. Part A-Appl S 38 (8) (2007) 1821-1828, https://doi.org/10.1016/j.compositesa.2007.04.009.

[9] G. Lebrun, M.N. Bureau, J. Denault, Evaluation of bias-extension and picture-frame test methods for the measurement of intraply shear properties of PP/glass commingled fabrics, Compos. Struct. 61 (4) (2003) 341-352, https://doi.org/ 10.1016/S0263-8223(03)00057-6.

[10] J. Domskienè, E. Strazdiené, Investigation of fabric shear behaviour, Fibres Text. East. Eur. 13 (2) (2005) 26-30.

[11] B. Al-Gaadi, M. Halász, Deformation analysis of composite reinforcing fabrics through yarn- pull-out, drape and shear tests, Fibers Polym. 14 (5) (2013) 804-814, https://doi.org/10.1007/s12221-013-0804-1.

[12] X.Q. Penga, J. Cao, J. Chen, P. Xue, D.S. Lussier, L. Liu, Experimental and numerical analysis on normalization of picture frame tests for composite materials, Compos. Sci. Technol. 64 (1) (2004) 11-21, https://doi.org/10.1016/S0266-3538 (03)00202-1.

[13] S. Orawattanasrikul, Experimentelle Analyse der Scherdeformation biaxial verstärkter Mehrlagengestricke, $\mathrm{PhD}$ Theses, Technische Universität Dresden, Fakultät Maschinenwesen, Dresden, 2006.

[14] S. Kawabata, The Standardization and Analysis of Hand Evaluation, Textile Machinery Society of Japan, Osaka, 1980.

[15] E.M. Parsons, M.J. King, S. Socrate, Modeling yarn slip in woven fabric at the continuum level: simulations of ballistic impact, J. Mech. Phys. Solids 61 (1) (2013) 265-292, https://doi.org/10.1016/j.jmps.2012.05.005.

[16] A.G. Prodromou, J. Chen, On the relationship between shear angle and wrinkling of textile composite preforms, Compos. Part A-Appl S 28 (5) (1997) 491-503, https://doi.org/10.1016/S1359-835X(96)00150-9.

[17] K. Bilisik, Properties of yarn pull-out in para-aramid fabric structure and analysis by statistical model, Compos. Part A-Appl S 42 (12) (2011) 1930-1942, https:// doi.org/10.1016/j.compositesa.2011.08.018.

[18] G. Nilakantan, J.W. Jr Gillespie, Yarn pull-out behavior of plain woven Kevlar fabrics: effect of yarn sizing, pull-out rate, and fabric pre-tension, Compos. Struct. 101 (2013) 215-224, https://doi.org/10.1016/j.compstruct.2013.02.018.

[19] S. Das, S. Jagan, A. Shaw, A. Pal, Determination of inter-yarn friction and its effect on ballistic response of para-aramid woven fabric under low velocity impact, Compos. Struct. 120 (2015) 129-140, https://doi.org/10.1016/j. compstruct.2014.09.063.

[20] Z. Dong, C.T. Sun, Testing and modeling of yarn pull-out in plain woven Kevlar fabrics, Compos. Part A-Appl S 40 (12) (2009) 1863-1869, https://doi.org/ 10.1016/j.compositesa.2009.04.019.

[21] B. Al-Gaadi, Analysis of 3D Deformation Properties of Woven Composite Reinforcing Structures, $\mathrm{PhD}$ Theses, Budapest University of Technology and Economics, Budapest, 2012.

[22] N. Pan, M.-Y. Yoon, Behavior of yarn pull out from woven fabrics: theoretical and experimental, Text. Res. J. 63 (11) (1993) 629-637, https://doi.org/10.1177/ 004051759306301103.

[23] M. Valizadeh, S. Lomov, S.A.H. Ravandi, M. Salimi, S.Z. Rad, Finite element simulation of a yarn pull out test for plain woven fabrics, Text. Res. J. 80 (10) (2010) 892-903, https://doi.org/10.1177/0040517509346436.

[24] A. Kelly, W.R. Tyson, Tensile properties of fibre-reinforced metals: copper/ tungsten and copper/molybdenum, J. Mech. Phys. Solids 13 (6) (1965) 329-338, https://doi.org/10.1016/0022-5096(65)90035-9, in1-in2, 339-350.

[25] K. Bilisik, Experimental determination of fabric shear by yarn pull-out method, Text. Res. J. 82 (10) (2012) 1050-1064, https://doi.org/10.1177/ 0040517511431318 .

[26] R. Bai, W. Li, Z. Lei, Y. Ma, F. Qin, Q. Fang, X. Chen, Y. Chen, Experimental study of yarn friction slip and fabric shear deformation in yarn pull-out test, Compos. Part A-Appl S 107 (4) (2018) 529-535, https://doi.org/10.1016/j. compositesa.2018.02.001.

[27] B. El Abed, S. Msahli, H. Bel Hadj Salah, F. Sakli, Study of woven fabric shear behaviour, J. Text. Inst. 102 (4) (2011) 322-331, https://doi.org/10.1080/ 00405001003771226.

[28] R.H. Gong, A. Bhatia, Effects of softeners on mechanical properties of cotton fabric, Res. J. Text Appar. 13 (4) (2009) 45-50, https://doi.org/10.1108/RJTA-13-042009-B006.

[29] M. Shanbeh, M. Safar Johari, M. Zarrebini, M. Barburski, A. Komisarczyk, Analysis of shear characteristics of woven fabrics and their interaction with fabric integrated structural factors, J. Eng. Fiber Fabr. 14 (1) (2019) 1-13, https://doi. org/10.1108/RJTA-13-04-2009-B006. 